\title{
Crustal deformation and a preliminary fault model of the 2007 Chuetsu-oki earthquake observed by GPS, InSAR, and leveling
}

\author{
Takuya Nishimura, Mikio Tobita, Hiroshi Yarai, Shinzaburo Ozawa, Makoto Murakami*, Toru Yutsudo, Masayoshi Ishimoto, \\ Takeshi Umesawa, Takashi Toyofuku, Satoshi Kawamoto, Tomomi Amagai, Midori Fujiwara, Akira Suzuki, Syunji Enya, \\ Toshiyuki Sasaki, Masanori Yokokawa, Syuichi Oomori, Setsuo Tanoue, Hisao Ikeda, Moriyuki Nemoto, \\ Hisashi Suito, Fumi Hayashi, Hiroshi Une ${ }^{\dagger}$, Mamoru Koarai, and Masaharu Tsuzawa
}

Geographical Survey Institute, Tsukuba, Ibaraki, Japan

(Received November 30, 2007; Revised June 6, 2008; Accepted June 7, 2008; Online published November 18, 2008)

\begin{abstract}
The 2007 Chuetsu-oki earthquake occurred just west off the coast of Kashiwazaki in Niigata Prefecture, Central Japan on July 16, 2007. The permanent GPS network (GEONET) clarifies the coseismic displacement as a thrust faulting whose compressional axis lies in the NW-SE direction. Interferometric analysis of synthetic aperture radar (SAR) images acquired by "Daichi" satellite (ALOS) maps a detailed spatial pattern of the displacement toward the satellite for both ascending and descending orbits. Peak-to-peak displacement reaches approximately $400 \mathrm{~mm}$ in the descending orbit interferometric (In)SAR data. Repeated precise leveling shows uplift near the northeast part of the aftershock area and subsidence near the southwestern part. We construct a preliminary fault model by inverting the observed deformation. The preferred model consists of two segments of rectangular faults whose moment magnitude is 6.7 in total. From only the used geodetic data on land, it is difficult to determine which plane in two conjugate planes of the focal solution was ruptured. It is important to consider the effect of a heterogeneous medium and variable slip on the faults as well as other geophysical data to determine the fault model with confidence.
\end{abstract}

Key words: 2007 Chuetsu-oki earthquake, crustal deformation, GPS, InSAR, leveling.

\section{Introduction}

A shallow earthquake occurred near the coast of Niigata Prefecture, Central Japan on July 16, 2007 (Fig. 1). This earthquake, with a JMA (Japan Meteorological Agency) magnitude of 6.8 , was named the Niigataken Chuetsuoki earthquake in 2007 (hereafter, 2007 Chuetsu-oki earthquake) by the JMA. It caused approximately 2,400 casualties and damaged many buildings near the epicenter, especially in Kashiwazaki. The focal mechanism from the Centroid Moment Tensor (CMT) inversion determined by NIED (National Research Institute for Earth Science and Disaster Prevention) shows a thrust-type faulting with the compressional axis in the NW-SE direction. The epicenter of the main-shock is under the Sea of Japan, where most of the aftershocks also occurred. Although the Japanese islands are covered by dense arrays of geodetic and seismic networks, no geophysical measurements were conducted just above the source region of the earthquake because it occurred offshore. The spatial relation between the source and the observations has made it difficult for researchers to determine the source process and fault geometry of the 2007

*Present address: Graduate School of Science, Hokkaido University, Sapporo, Hokkaido, Japan.

${ }^{\dagger}$ Present address: College of Land, Infrastructure, Transport, and Tourism, Kodaira, Tokyo, Japan.

Copyright (c) The Society of Geomagnetism and Earth, Planetary and Space Sciences (SGEPSS); The Seismological Society of Japan; The Volcanological Society of Japan; The Geodetic Society of Japan; The Japanese Society for Planetary Sciences; TERRAPUB.
Chuetsu-oki earthquake.

It is notable that the earthquake occurred in the NiigataKobe tectonic zone (NKTZ), where the geodetic strain rate is higher than that in the surrounding region. Sagiya et al. (2000) proposed the existence of this NKTZ based on the spatial distribution of contemporary strain rates from a Japanese permanent GPS array (GEONET) and the frequent occurrence of crustal earthquakes. One of the earthquakes that has occurred in the NKTZ is the $M_{\mathrm{JMA}} 6.82004$ Chuetsu (Mid Niigata Prefecture) earthquake (Aoki et al., 2005) on October 23, 2004. Its epicenter locates only 40 $\mathrm{km}$ southeast of that of the 2007 Chuetsu-oki earthquake (Fig. 1).

Here, we discuss coseismic displacement of the 2007 Chuetsu-oki earthquake using several geodetic techniques, including continuous GPS, synthetic aperture radar (SAR) interferometry, and leveling. These geodetic data revealed a detailed spatial pattern of the coseismic deformation. Using these data, we also construct a preliminary fault model explaining the observed deformation.

\section{Coseismic Deformation \\ 2.1 GPS}

Significant coseismic deformation associated with the 2007 Chuetsu-oki earthquake was observed at permanent GPS stations in Central Japan. The Japanese islands are covered by the permanent GPS array, GEONET, which is operated by the Geographical Survey Institute (GSI) and consists of approximately 1,200 continuous sites (e.g., 


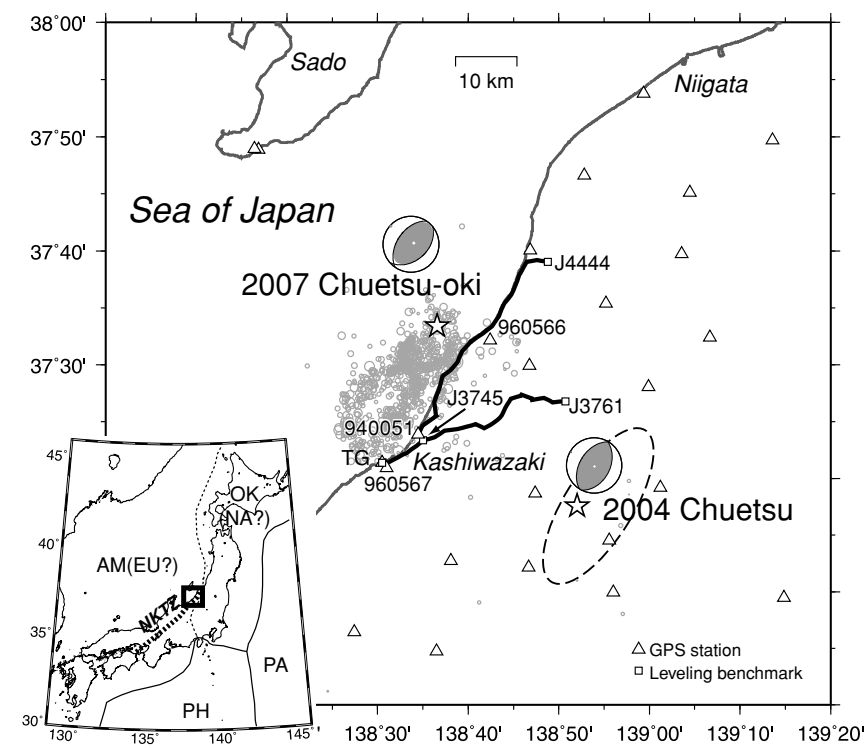

Fig. 1. Location map showing an epicenter of the 2007 Chuetsu-oki earthquake and geodetic stations. Open triangles represent the permanent GPS stations. Thick lines represent leveling routes with terminal and junction benchmarks denoted by open squares. Station codes of the selected GPS stations and leveling benchmarks are denoted. TG is the Kashiwazaki tide gauge station where leveling benchmarks and the permanent GPS stations are located. A star and gray circles represent epicenters of the mainshock and aftershocks of the 2007 Chuetsu-oki earthquake determined by JMA, respectively. The epicenter and aftershock region of the 2004 Chuetsu earthquake are shown by a star and a dashed ellipsoid, respectively. Beach balls represent CMT solution for the focal mechanism determined by NIED (National Research Institute for Earth Science and Disaster Prevention). Abbreviations in the tectonic map (inset) are OK, NA, PA, PH, EU, AM, and NKTZ for Okhotsk, North American, Pacific, Philippine Sea, Eurasia, Amurian plates, and Niigata Kobe Tectonic Zone, respectively. The rectangular area in the tectonic map corresponds to the location map.

(a)

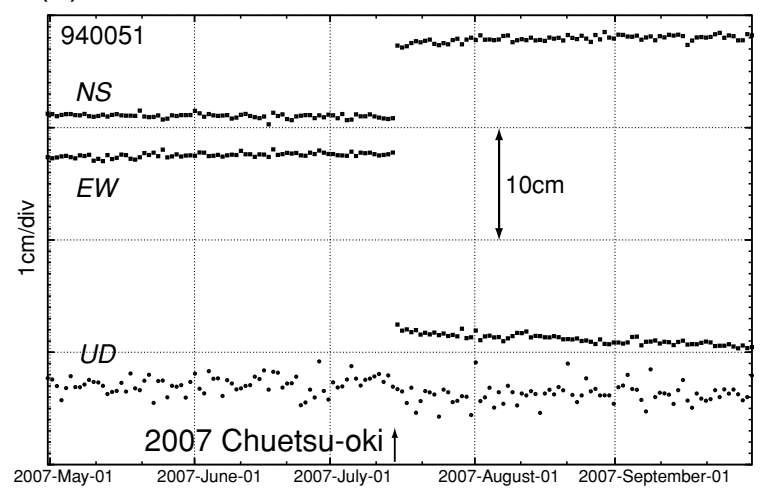

(b)

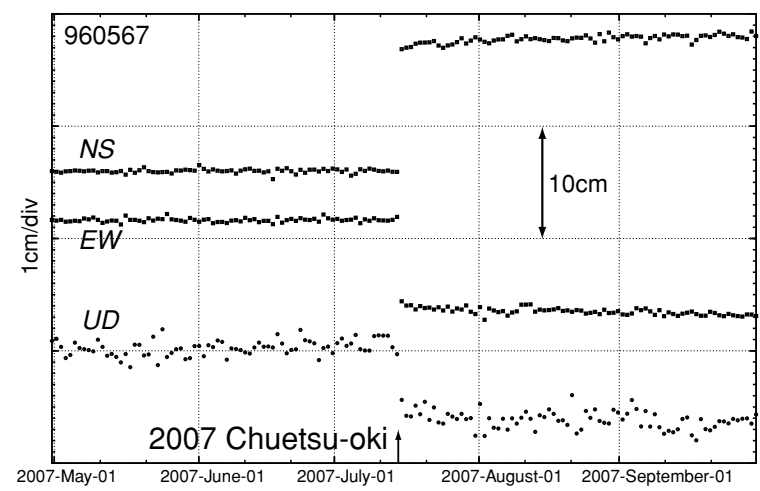

Fig. 2. Time-series of the selected GPS stations. Daily coordinates with respect to the Toyama (950249) station are plotted. Arrows indicate the date when the 2007 Chuetsu-oki earthquake occurred.

Sagiya et al., 2000; Sagiya, 2004). The daily coordinates of the GEONET stations are obtained with Bernese GPS software version 4.2 and IGS (International GNSS Service) final ephemeredes. We use these coordinates, called the GEONET final (F2) solution, in this study.

Time-series of the daily coordinates of the selected stations relative to that of Toyama (950249) station show clear coseismic offsets and postseismic transitions (Fig. 2). The coseismic displacement at the reference station can be ignored because it is a long distance (approx. $160 \mathrm{~km}$ ) from the epicenter. Following coseismic displacement, the significant postseismic displacement can be recognized to reach approximately $10 \mathrm{~mm}$ for 1 month after the earthquake.

The maximum horizontal displacement is approximately $170 \mathrm{~mm}$ to the west-northwest of station 940051 (Fig. 3(a)).
Subsidence is significant at several stations south of the epicenter, and the plotted coseismic displacement is taken to be the difference in the average positions of daily solutions between July 6 and July 15 and between July 17 and July 26,2007 . The spatial pattern of the coseismic displacement suggests compression in the NW-SE direction, which is in agreement with the focal mechanism shown in Fig. 1. On site measurements suggest that the large displacement observed at station 960566, which is located just east of the epicenter, is contaminated by the local disturbance and the monument instability. We, therefore, use a much smaller weight for station 960566 to estimate the fault model. Tiltmeters and on site measurement confirms that the GPS pillar of station 960567 is also tilted by strong ground shaking. The displacement plotted in Fig. 3 is corrected for pillar tilting by subtracting the antenna displacement relative to the 
(a)

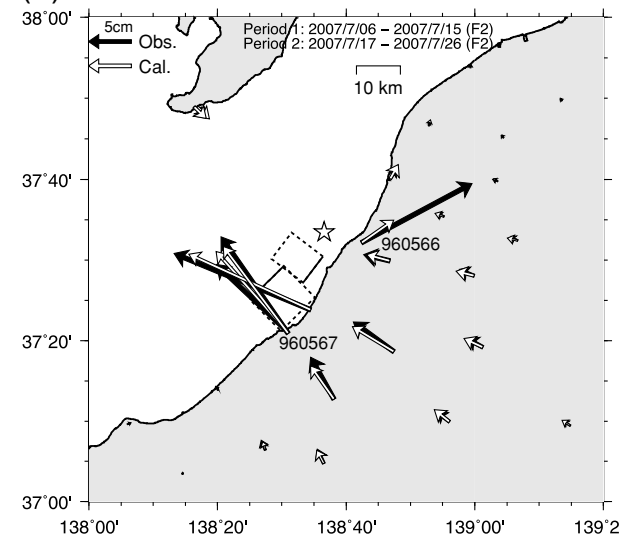

(b)

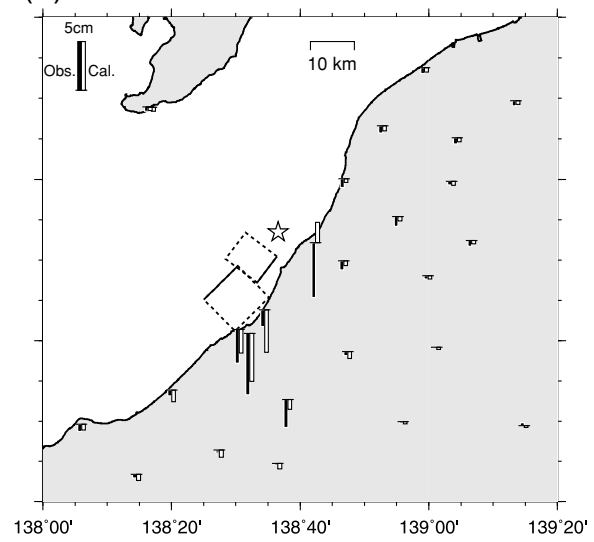

Fig. 3. Coseismic displacement of the 2007 Chuetsu-oki earthquake at permanent GPS stations. A star represents an epicenter of the main-shock. The plotted displacement is relative to the Toyama (950249) station. The dotted rectangles show the fault location of the estimated rectangular faults. The solid line on the rectangles shows the upper edge of the fault. (a) Horizontal displacement. Solid and open arrows represent observed and calculated displacements, respectively. (b) Vertical displacement. Solid and open bars represent observed and calculated displacements, respectively.

base.

\subsection{InSAR}

We used SAR data acquired by "Daichi" (ALOS, Advanced Land Observing Satellite) of the Japan Aerospace Exploration Agency (JAXA). The SAR data taken in the descending (January 16 and July 19) and ascending (June 14 and September 14) orbits were processed to generate an interferogram (In). The GSI 50-m grid digital elevation model (DEM) is used to remove topographic fringes by the twopass approach. The SAR interferogram represents the displacement in the line of sight (LOS) to the satellite. The unitary vector of LOS in its descending and ascending orbits are $(0.637,-0.113,0.762)$ and $(-0.620,-0.109,0.777)$ in a coordinate set (east, north, up), respectively. In these interferograms, negative LOS displacement means movement to the satellite - that is, range decrease between the ground and satellite. A clear deformation signal is seen in the coherent part of the image. A large displacement of approximately $300 \mathrm{~mm}$ was recognized south of the epicenter in the interferogram for the descending orbit (Fig. 4(a)). In contrast, the maximum displacement is approximately $150 \mathrm{~mm}$ in that for the ascending orbit (Fig. 4(d)).

The LOS displacement is plotted on four profiles perpendicular to the strike of the Chuetsu-oki earthquakes (Fig. 5). On the northern three profiles $\left(\mathrm{A}-\mathrm{A}^{\prime}, \mathrm{B}-\mathrm{B}^{\prime}\right.$, and $\left.\mathrm{C}-\mathrm{C}^{\prime}\right)$, the LOS displacement for the descending orbit decreases towards the aftershock region and has the lowest value near the coast. However, it increases towards the aftershock region on the southernmost profile $\left(\mathrm{D}-\mathrm{D}^{\prime}\right)$. For the ascending orbit, four profiles show the LOS displacement is not large. This contrast between the descending and ascending data suggests the coseismic displacement is roughly perpendicular to the direction of LOS for the ascending orbit.

It is very interesting to note that the largest displacement for ascending data was observed not near the epicenters but in the Nishiyama hill, $6 \mathrm{~km}$ east of the coast (Fig. 4(d)). This pattern can be recognized as a large displacement recorded at $6 \mathrm{~km}$ of the horizontal axis in profile B-B' for the ascending orbit (Fig. 5). It is difficult to explain this spatial pattern by the fault models located in the aftershock area. Nishimura et al. (2008) studied this deformation in detail, and this paper focuses on the deformation near the epicenter.

\subsection{Leveling}

The 2007 Chuetsu-oki earthquake occurred near the firstorder leveling route conducted by GSI (Fig. 1). One of the leveling routes is located along the coast (hereafter route A), and the other goes from station BM J3745 in Kashiwazaki and proceeds inland (hereafter route $\mathrm{B}$ ). These routes were leveled in September to October 2006 before the earthquake. The postseismic measurements were conducted in two periods: (1) July 20 to August 9, 2007; (2) September 21 to October 4, 2007. During the first period, most of route A, except for the northernmost part (e.g., from stations BM TG to BM 4451) and the western part of route B (e.g., from stations BM J3745 to BM 3749), was leveled. During the second period (September 21 to October 4, 2007), the northernmost and southern part of route A (e.g., from stations BM 4451 to BM J4444 and from stations BM TG to BM J3745) and all of route B was leveled. We used the data for the first period if the benchmarks had been leveled twice after the earthquake.

The vertical displacement observed by leveling surveys is roughly characterized by the uplift near the northern part of the aftershock area and the subsidence near its southern part (Fig. 6). The displacement in Fig. 6 is not absolute but a relative one for plotting. The maximum uplift of $264 \mathrm{~mm}$ with respect to station BM J4444 is observed at station BM 4458 near the northern part of the aftershock area. The maximum subsidence is $302 \mathrm{~mm}$ at BM 4461 with respect to BM J4444. Large troughs at BM 4461 and BM 3744 may be caused by the local effect, such as soil liquefaction and lateral soil flow, because they locate in an incoherent part of the SAR interferograms (Fig. 4(a, d)). We do not use the data at BM 4461 and BM 3744 to avoid the contamination of the local effect for the estimation of the fault model. The benchmark at the Kashiwazaki tide gauge station (hereafter BM TG) subsided by $26 \mathrm{~mm}$ with respect to BM J4444. The subsidence of BM TG measured by continuous GPS and sea level is $35 \mathrm{~mm}$ and approximately $35 \mathrm{~mm}$, respec- 
(a)

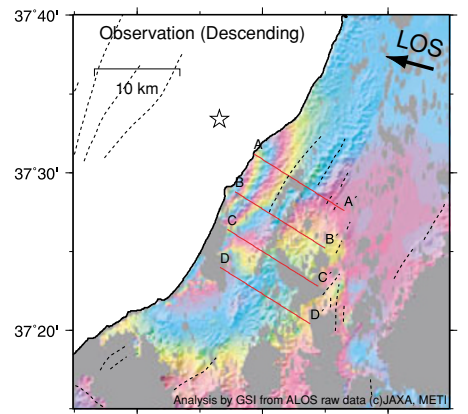

(d)

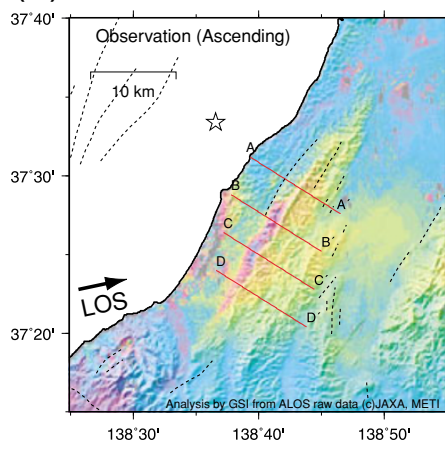

(b)

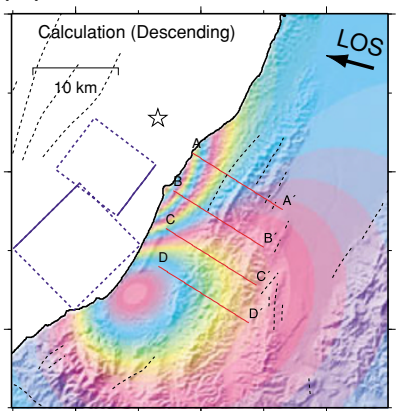

(e)

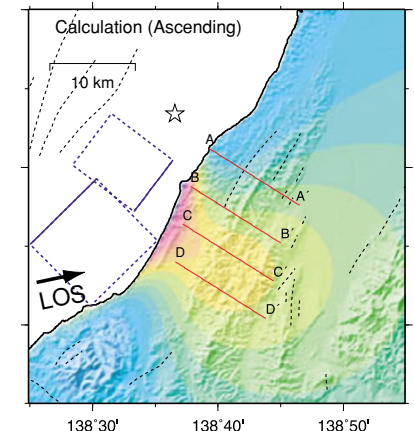

$138^{\circ} 30^{\prime} \quad 138^{\circ} 40^{\prime} \quad 138^{\circ} 50^{\prime}$ (c)

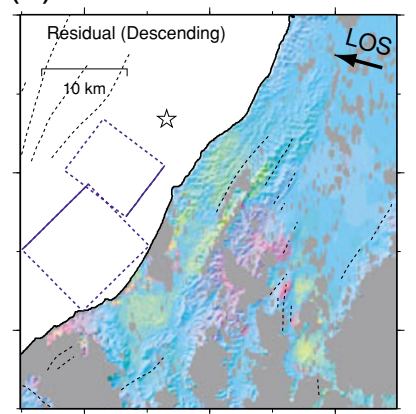

(f)

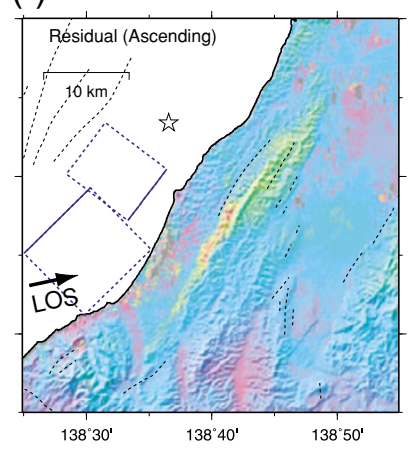

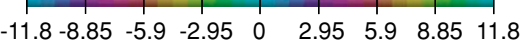

LOS Displacement $(\mathrm{cm})$

Fig. 4. Interferograms of the synthetic aperture radar onboard the "Daichi" satellite (ALOS) showing the displacement of the 2007 Chuetsu-oki earthquake. A-A', B-B', C-C', and D-D' represent four profiles on which the line of sight (LOS) displacement are shown. The thin dashed lines denote active fault traces (Research Group for Active Faults of Japan, 1991). The dotted rectangle shows the fault location of the best-fit model. The solid line on the rectangles shows the upper edge of the fault. The arrow indicates the horizontal projection of the LOS direction. (a) Observed interferogram formed from the descending orbit data acquired on January 16 and July 19, 2007. The gray area indicates bad coherence of two radar images. The perpendicular component of the orbit baseline $\left(B_{\text {perp }}\right)$ is $-300 \mathrm{~m}$. (b) Descending orbit interferogram calculated using the fault model. (c) Residual interferogram for the descending orbit data. (d) Observed interferogram formed from the ascending orbit data acquired on June 14 and September 14, 2007. The gray area indicates bad coherence of two radar images. The perpendicular component of the orbit baseline ( $\left.B_{\text {perp }}\right)$ is $653 \mathrm{~m}$. (e) Ascending orbit interferogram calculated using the fault model. (f) Residual interferogram for the ascending orbit data.
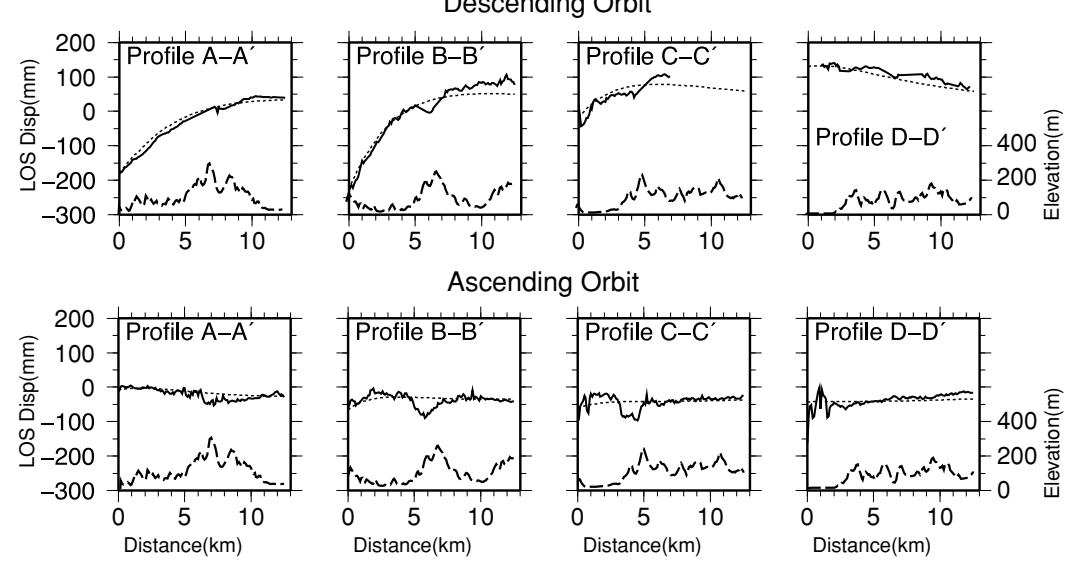

Fig. 5. Observed and calculated LOS displacements on the profiles A-A', B-B', C-C $\mathrm{C}^{\prime}$, and D-D'. The upper and lower panels show the descending and ascending orbit data, respectively. The location of the profiles is shown in Fig. 4. Solid, dotted, and dashed lines represent the observed displacements, the calculated displacements, and elevation, respectively.

tively. Measurements by three different methods confirm subsidence of BM TG to be within uncertainties of approximately $10 \mathrm{~mm}$.

\section{Modeling}

For a preliminary model, we estimate a rectangular fault model on which slip is uniform. We invert the observed deformation to estimate the fault model. Because we have data observed by different techniques, we must weigh the 

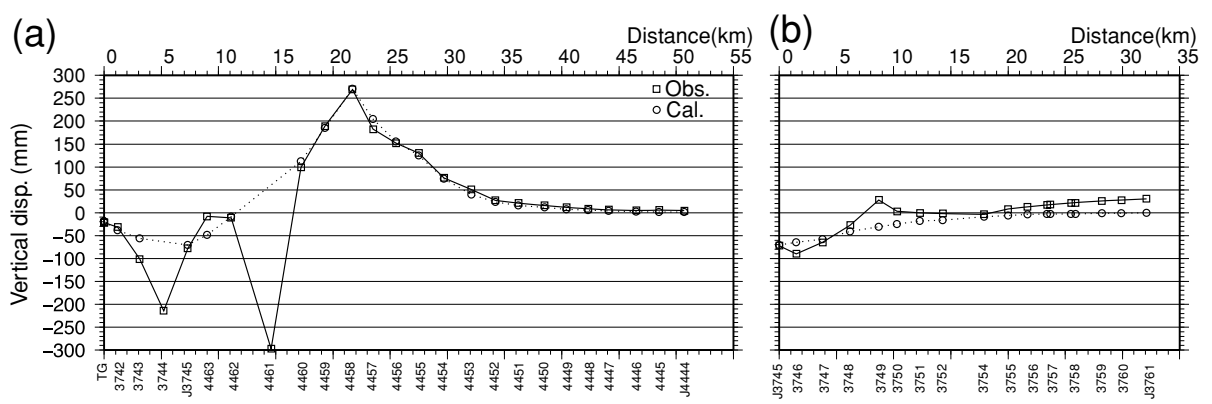

Fig. 6. Vertical displacement along the leveling routes from BM TG to BM J4444 and from BM J3745 to BM J3761. The leveling was conducted in September to October, 2006 (before the earthquake) and in July to October, 2007 (after the earthquake). Squares and circles indicate observed and calculated displacement, respectively. Numbers at the bottom represent benchmark codes.

Table 1. Estimated fault parameters.

\begin{tabular}{|c|c|c|c|c|c|c|c|c|c|}
\hline & $\begin{array}{c}\text { Latitude* }^{*} \\
\left({ }^{\circ}\right)\end{array}$ & $\begin{array}{l}\text { Longitude* } \\
\left({ }^{\circ}\right)\end{array}$ & $\begin{array}{c}\text { Depth* } \\
(\mathrm{km})\end{array}$ & $\begin{array}{c}\text { Length } \\
(\mathrm{km})\end{array}$ & $\begin{array}{l}\text { Width } \\
(\mathrm{km})\end{array}$ & $\begin{array}{c}\text { Strike } \\
\left({ }^{\circ}\right)\end{array}$ & $\begin{array}{l}\text { Dip } \\
\left({ }^{\circ}\right)\end{array}$ & $\begin{array}{c}\text { Rake } \\
\left({ }^{\circ}\right)\end{array}$ & $\begin{array}{l}\text { Slip } \\
\text { (m) }\end{array}$ \\
\hline Segment 1 & 37.508 & 138.607 & 5.2 & 7.6 & 10.6 & 217 & 32 & 127 & 2.85 \\
\hline Segment 2 & 37.419 & 138.417 & 2.2 & 11.0 & 11.3 & 45 & 26 & 94 & 1.35 \\
\hline
\end{tabular}

*Location of the corner measuring strike on the upper edge of the fault plane.

data for the inversion analysis. For the permanent GPS data, we calculated standard deviations of daily relative coordinates for every component and assigned them as data uncertainties. The uncertainties are on the order of 1.0-4.4 mm for the horizontal components and 5.7-13 $\mathrm{mm}$ for the vertical components. We used uncertainties of 100-200 $\mathrm{mm}$ for the 960566 station with the monument instability. The total number of permanent GPS stations used in the inversion is 47. Because there are no straightforward ways to assign uncertainties for InSAR data, we assumed them arbitrarily. Millions of data points exist in the interferogram. We reduced data points to 367 and 503 points for descending and ascending data, respectively, and we assigned $20 \mathrm{~mm}$ as the data uncertainties. The data points are manually picked to avoid decorrelation areas and errors of phase unwrapping in the interferograms. For the leveling data, we used the relative displacement in the section between two adjacent benchmarks. We assigned the uncertainties in the range $0.5-8.6 \mathrm{~mm}$, which is fivefold the average measurement errors for the recent first-order leveling in Japan. The total number of all data is 1052 .

The synthetic surface deformation is calculated using the formulation of Okada (1985) assuming a dislocation source in an elastic half-space. We used the nonlinear inversion method developed by Matsu'ura and Hasegawa (1987) to estimate parameters of a rectangular fault. This method uses a constraint that the parameters are close to the initial ones as prior information. In addition to solving for the fault parameters (e.g., location, depth, length, width, strike, dip, rake, and slip), we determine the offsets in LOS displacement for the ascending and descending orbit to account for ambiguities in the zero displacement level of the InSAR data.

We first tried to explain the observed displacement by a single rectangular fault. However, it was impossible to fit the displacement observed by GPS and InSAR, especially near the aftershock region. It is apparent that the fault is oriented in the NE-SW direction, as clearly shown by the focal mechanism and the aftershock distribution (Fig. 1). We divided a rectangular fault into NE and SW segments in strike direction and estimated the fault parameters for two rectangular segments.

Inversion results depend on the initial parameters because of the non-linearity of the parameters and the inversion method. After trial and error modeling, we used four sets for fault dip as the initial parameters: one is that both segments of the faults dip northwest; another is that both segments of the faults dip southeast; the others are combinations of NW-dipping and SE-dipping segments. The parameters of strike, length, and width are loosely constrained to be the initial ones based on the focal mechanism and the size of aftershock areas. The data residuals were normalized by the data uncertainties - that is, chi-squared statistics range between 1,135 and 1,350 for the four sets of initial parameters. These residuals are much smaller than that of approximately 2,000 for the single-segment model. The calculated $F$-statistics between the single-segment and twosegment model is more than 55. Because the $F$-statics is well above the $99 \%$ confidence level of 2.42 , we need to divide the source fault into two segments to explain the observed deformation. In this paper, we adopted the model that the NE and SW segments dip northwest and southeast, respectively, since this gives the smallest residuals among four sets. The estimated parameters are listed in Table 1. Assuming a rigidity of $30 \mathrm{GPa}$, the seismic moment is $1.2 \times 10^{19} \mathrm{~N} \cdot \mathrm{m}\left(M_{\mathrm{w}} 6.7\right)$. The displacement calculated by the model is compared with the observed one in Figs. 3-6.

\section{Discussion}

The best-fit model reproduces the observed deformation very well. However, the geodetic data cannot determine the fault geometry because the other three models with different dipping directions also explain the observed deformation reasonably. Although the dense geodetic measurements reveal a detailed spatial pattern of the coseismic deformation, the geodetic data on land is not a deciding factor for chos- 
ing one of the nodal planes of the focal mechanism for the 2007 Chuetsu-oki earthquake. This fact is a reminder that the earthquake is modeled by a double couple and that two conjugate fault planes only have a different pattern of surface deformation near the source. Nevertheless, we recognize differences in the deformation predicted by four models. The model of the SW segment dipping southeast, including the best-fit one, fits the direction of horizontal displacement at three nearby stations in Kashiwazaki city (e.g., 940051, 960567, and the other) compared with the model dipping northwest. The best-fit model in which the NE segment dips northwest reproduces the LOS displacement on profile B-B' for both orbits (Fig. 5). The model of the NW segment dipping SE gives the worse fitting near the distance of $0 \mathrm{~km}$. We therefore suggest that the geodetic data favor the NE segment dipping northwest and the SW segment dipping southeast for the fault model of the 2007 Chuetsu-oki earthquake.

Although the aftershock distribution determined by JMA on the routine basis depicts a rough alignment dipping southeast, a complex pattern showing alignments dipping both southeast and northwest can be recognized. One of the significant differences between aftershock distribution and the geodetic model is the depth of the source area. The aftershock distributes in a depth of $15-25 \mathrm{~km}$. On the other hand, the fault model is estimated at a depth of 2.2-10.8 km. Seismic tomography studies (e.g., Nakajima and Hasegawa, 2007; Kato et al., 2008) show that the sediment down to a depth of $6 \mathrm{~km}$ covers the NE part of NKTZ, including the epicentral area. We need to consider the effect of the sediment having low seismic velocities and small elastic moduli. A low-elastic modulus layer causes the halfspace equivalent dislocation to appear at a shallower depth than the actual dislocation in the layered half space (Savage, 1998). Modeling of the surface deformation including the layered half-space and variable slip on the faults is the next step of our analysis. The precise hypocenter of the aftershocks determined by Kato et al. (2008) and Shinohara et al. (2008) shows that the actual depth of the hypocenters are much shallower than that determined by JMA and that the major alignment of the aftershocks dips to southeast. To determine the fault geometry of the 2007 Chuetsu-oki earthquake, we should consider not only the geodetic data but also the geophysical data, especially, aftershock distribution (e.g., Kato et al., 2008; Shinohara et al., 2008). It is also important to understand the role of the 2007 Chuetsu-oki earthquake within the framework of geomorphologic and tectonic studies because the area is one of the best-studied active fold belts in Japan (e.g., Ikeda, 2002).

\section{Conclusion}

The coseismic deformation of the 2007 Chuetsu-oki earthquake is observed by geodetic survey of GPS, InSAR, and leveling. These observations reveal a detailed spatial pattern of the deformation. The maximum displacement reaches approximately $300 \mathrm{~mm}$ on the coast of the Sea of Japan. The horizontal displacement observed by GPS suggests compression in the NW-SE direction, which is in agreement with the focal mechanism estimated from seismic data. Despite the existence of a dense and pre- cise geodetic network in place, it is difficult to determine the fault geometry, such as dipping direction, solely from the land geodetic data. A plausible model fitting the observed data consists of the NE segment dipping northwest and the SW one dipping southeast. Its moment magnitude is $M_{\mathrm{w}}$ 6.7. Modeling including a heterogeneous medium and variable slip on the fault with the other geophysical data is necessary to understand the complex fault mechanism of the 2007 Chuetsu-oki earthquake.

Acknowledgments. We thank Chuck Wicks and an anonymous reviewer for their careful review of our article. The hypocenter data were provided by the Japan Meteorological Agency in cooperation with the Ministry of Education, Culture, Sports, Science, and Technology. Synthetic aperture radar data acquired by the Daichi satellite (ALOS) were provided by JAXA through "Joint Cooperative Agreement between GSI and JAXA for observation of geographic information using Advanced Land Observing Satellite (ALOS) data." The figures were generated using the GMT (Generic Mapping Tools) package by Paul Wessel and Walter H. F. Smith.

\section{References}

Aoki, S., M. Nishi, K. Nakamura, T. Hashimoto, S. Yoshikawa, and H. M. Ito, Multi-planar structures in the aftershocks distribution of the Mid Niigata prefecture Earthquake in 2004, Earth Planets Space, 57, 411416, 2005.

Ikeda, Y., The origin and mechanism of active folding in Japan, Active Fault Research, 67-70, 2002 (in Japanese with English abstract).

Kato, A., S. Sakai, E. Kurashimo, T. Igarashi, T. Iidaka, N. Hirata, T. Iwasaki, T. Kanazawa, and Group for the aftershock observations of the 2007 Niigataken Chuetsu-oki Earthquake, Imaging heterogeneous velocity structures and complex aftershock distributions in the source region of the 2007 Niigataken Chuetsu-oki Earthquake by a dense seismic observation, Earth Planets Space, 60, this issue, 1111-1116, 2008.

Matsu'ura, M. and Y. Hasegawa, A maximum likelihood approach to nonlinear inversion under constraints, Phys. Earth Planet. Inter., 47, 179$187,1987$.

Nakajima, J. and A. Hasegawa, Deep crustal structure along the NiigataKobe Tectonic Zone, Japan: Its origin and segmentation, Earth Planets Space, 59, e5-e8, 2007.

Nishimura, T., M. Tobita, H. Yarai, T. Amagai, M. Fujiwara, H. Une, and M. Koarai, Episodic growth of fault-related fold in northern Japan observed by SAR interferometry, Geophys. Res. Lett., 35, L13301, doi:10.1029/2008GL034337, 2008.

Okada, Y., Surface deformation due to shear and tensile faults in a halfspace, Bull. Seismol. Soc. Am., 75, 1135-1154, 1985.

Research Group for Active Faults of Japan, Active Faults in Japan: sheet maps and inventories (Revised ed.), 437 pp., University of Tokyo Press, Tokyo, 1991 (in Japanese).

Sagiya, T., A decade of GEONET: 1994-2003-The continuous GPS observation in Japan and its impact on earthquake studies, Earth Planets Space, 56, 39-41, 2004.

Sagiya, T., S. Miyazaki, and T. Tada, Continuous GPS array and presentday crustal deformation of Japan, Pure Appl. Geophys., 157, 23032322, 2000.

Savage, J. C., Displacement field for an edge dislocation in a layered halfspace, J. Geophys. Res., 103, 2439-2446, 1998.

Shinohara, M., T. Kanazawa, T. Yamada, K. Nakahigashi, S. Sakai, R. Hino, Y. Murai, A. Yamazaki, K. Obana, Y. Ito, K. Iwakiri, R. Miura, Y. Machida, K. Mochizuki, K. Uehira, M. Tahara, A. Kuwano, S. Amamiya, S. Kodaira, T. Takanami, Y. Kaneda, and T. Iwasaki, Precise aftershock distribution of the 2007 Chuetsu-oki Earthquake obtained by using an ocean bottom seismometer network, Earth Planets Space, 60, this issue, 1121-1126, 2008.

T. Nishimura (e-mail: t_nisimura@gsi.go.jp), M. Tobita, H. Yarai, S. Ozawa, M. Murakami, T. Yutsudo, M. Ishimoto, T. Umesawa, T. Toyofuku, S. Kawamoto, T. Amagai, M. Fujiwara, A. Suzuki, S. Enya, T. Sasaki, M. Yokokawa, S. Oomori, S. Tanoue, H. Ikeda, M. Nemoto, H. Suito, F. Hayashi, H. Une, M. Koarai, and M. Tsuzawa 